Original article

\title{
Contraceptive choices following first childbirth among working women in Udupi taluk
}

\author{
Prashanthi Kamath, A.P Rao*, Prakash Narayanan \\ Department of Public Health, Manipal University, Manipal, India
}

\section{A R T I C L E I N F O}

\section{Article history:}

Received 30 July 2017

Accepted 26 October 2017

Available online 6 November 2017

\section{Keywords:}

Contraception

Working women

Post first childbirth

\begin{abstract}
A B S T R A C T
Introduction: Birth control is an important determinant of maternal survival. Contraceptive use helps the couple to have the desired number of children in the family as well as to practice the desired birth interval between pregnancies.

Objectives: (1) To study the choices of contraceptive method by working women following the first childbirth. (2) To study the factors influencing the decision making for the contraception by these working women.

Materials and methods: A community-based cross sectional study of 178 women from urban and rural parts was done using a semi-structured questionnaire at Udupi taluk, Karnataka. $30 \times 7$ cluster sampling technique was followed. Systematic random sampling was done to select total 30 clusters from urban and rural areas.

Results: It was shown that mean age of women was $29 \pm 3.516$ years, husbands' mean age was $33 \pm 4.711$. Majority (74.7\%) of the women were from rural area. Majority (99.4\%) had knowledge of contraceptives but only $43 \%$ were practicing contraception. Majority (44.9\%) were using copper T. Health concern (60.7\%) was the major factor influencing decision making about family planning services. Majority (91.6\%) couples took joint decision about contraception.

Conclusion: Although the awareness of contraceptives among working women was high, less than half of the women were practicing contraception. Copper T was used by the majority of working women. Fear of side-effects was the major concern among non-users of contraceptives. Decision making was based on the mutual discussion between the couple.
\end{abstract}

(C) 2017 Published by Elsevier, a division of RELX India, Pvt. Ltd on behalf of INDIACLEN.

\section{Introduction}

World Health Organization defines family planning as "a way of thinking and living that is adopted voluntarily, upon the basis of knowledge, attitudes and responsible decision by individuals and couples, in order to promote the health and welfare of family groups and thus contribute effectively to the social development of a country". ${ }^{-}$In developing countries, contraception has an important role in promoting maternal and child health. Contraceptive use helps the couple to have the desired number of children in the family as well as to practice the desired birth interval between pregnancies. ${ }^{2}$ When a couples practice contraception, it reduces unintended pregnancies that in turn reduces need for unsafe abortions. $^{1}$

According to WHO, 225 million women in developing countries have a desire to terminate fertility or postpone childbearing but

\footnotetext{
* Corresponding author.

E-mail address: arathimph@gmail.com (A.P. Rao).
}

they are not practicing any method of contraception. ${ }^{1}$ Worldwide most of the regions reported one in ten married or an in-union woman has an unmet need for family planning. The different reasons for global unmet need are limited access, limited choices of contraceptives especially for the young people who are unmarried and belongs poor segment of society. ${ }^{2}$

In India, $77 \%$ of females never adopted any contraceptive methods before terminating their fertility. It is also reported that $11 \%$ of births take place within 18 months of last birth and $28 \%$ occur within 24 months of last birth. ${ }^{5}$ To a large extent, current contraceptive users are ones who have already achieved their family size. Data indicate that the program has not so far succeeded in providing contraceptives to delay the first birth and to space subsequent births. ${ }^{5,6}$

Due to high female literacy in Udupi district, women have greater occupational choices which make her economically independent and she can take a responsible decision of reproductive choices. That also helps working women to balance work and home effectively. ${ }^{6} \mathrm{~A}$ woman's individual decision making power or decision taken along with partner is an important factor in 
contraceptive use. ${ }^{7}$ Formal education, nuclear family, religious values, higher ages of married women, occupational status, employment and number of living children were observed to have positive impact on the use of contraception. ${ }^{7,8}$ Objectives of the study were, to study the choices of contraceptive method by working women following the first childbirth and to study the factors influencing the decision making for the contraception by these working women.

\section{Materials and methods}

A community based cross sectional study was conducted in urban and rural parts of Udupi taluk for a period of six months from January 2017 to June 2017. Study population comprised of working women who are first time mothers with their living child who completed six months to 24 months irrespective of their current reproductive status. Widows and separated, married woman who are not staying with their husband, women who have undergone hysterectomy were excluded from the study. Sampling technique followed was WHO recommended ' $30^{*} 7$ ' cluster sampling. Each cluster was more likely to have similar characteristics. Seven samples from each cluster constituted a representative sample of urban and rural community. Sampling frame was developed referring the 2011 Census data for Udupi district. Villages with smaller number of households were combined into one big cluster at par with the bigger ones. A total of 30 clusters (10 urban and 20 rural) were selected by systematic random sampling from the list of Census villages and wards. Estimated sample size was 210. Due to feasibility reasons total, 178 women were interviewed. Total 19 villages from rural area and six wards from urban areas were interviewed. Working women were defined as women with one living child of six to 12 months old, employed in any form of part time and full-time occupation. ASHA and Anganwadi workers were contacted to list out the working women who met inclusion criteria, from which random selection was done to select samples. Working women classification in NFHS-3 data was followed to identify working women. Engineers, nurses, medical and other health technicians, accountants, executive and administrative related workers were classified as professionals. Librarians, cashiers, transport supervisors and clerical workers were classified as clerical group. Shop keepers and shop assistants were classified as sales. Women involved in agriculture and fishing were classified as agricultural employees. Cooks, domestic and housekeeping service workers, beauticians, tailors, daily wage laborers were classified into services, skilled and unskilled workers. Since working women were interviewed in the study, data collection was done in the evening at their household. A semi-structured questionnaire was used to collect data. Content of the tool was validated by the expert opinion. Tool domains were sociodemographic information, knowledge questionnaires on contraception, reproductive behavior and current use of contraception, and decision making questionnaires. Data were analyzed in Statistical package for social sciences version 16. Socio-demographic information and current use of contraception were categorized and reported using frequencies and percentage. Chisquare was performed to look association between sociodemographic data and use of contraception. Ethical clearance was taken from Institutional Ethical Committee, Kasturba Medical College and Kasturba Hospital (IEC 897/2016).

\section{Results}

Mean age of participants was $29 \pm 3.516$ years. Husbands' mean age was $33 \pm 4.711$. Majority (74.7\%) were from rural areas, $25.3 \%$ were from urban areas. Majority (85.4\%) were Hindu by religion. All the participants were literates. Out of $178,51(28.7 \%)$ had studied up to secondary school or less and 127 (71.3\%) had studied higher secondary and above. Most of them (42.2\%) were working as professionals, technicians and managerial workers. Out of 178,124 (69.7\%) had monthly income 10,000 rupees or less. Most of the participants belong to nuclear family (48.3\%), 37.1\% joint family and $26(14.6 \%)$ extended family. In both urban and rural areas majority were residing in nuclear family. Mean duration of marriage was $40.40 \pm 14.613$ months. Mean age of living child was $15.42 \pm 5.833$ months. Sex distribution of living child showed 88 (49.4\%) males and 90 (50.6\%) were females (Table 1 ).

All the participants except one were aware of at least one modern contraceptive method. Contraceptive awareness for any

Table 1

Socio-demographic profile of participants by place of residence $(n=178)$.

\begin{tabular}{|c|c|c|c|}
\hline Variables & $\begin{array}{l}\text { Urban } \\
n \text { (column \%) }\end{array}$ & $\begin{array}{l}\text { Rural } \\
n \text { (column \%) }\end{array}$ & $\begin{array}{l}\text { Total } \\
178 \text { (column \%) }\end{array}$ \\
\hline \multicolumn{4}{|l|}{ Income } \\
\hline Less than 10,000 & $28(62.2)$ & $96(72.1)$ & $124(69.7)$ \\
\hline $10,001-20,000$ & $12(26.7)$ & $32(24.1)$ & $44(24.7)$ \\
\hline $20,001-30,000$ & $3(6.7)$ & $3(2.3)$ & $6(3.4)$ \\
\hline $30,001-40,000$ & $2(4.4)$ & $2(1.5)$ & $4(2.2)$ \\
\hline \multicolumn{4}{|l|}{ Religion } \\
\hline Hindu & $40(88.9)$ & $112(84.2)$ & $152(85.4)$ \\
\hline Muslim and Christian & $5(11.1)$ & $21(15.8)$ & $26(14.6)$ \\
\hline \multicolumn{4}{|l|}{ Educational status } \\
\hline Secondary or less & $16(35.6)$ & $35(26.3)$ & $51(28.7)$ \\
\hline Higher secondary and above & $29(64.4)$ & $98(73.7)$ & $127(71.3)$ \\
\hline \multicolumn{4}{|l|}{ Occupation } \\
\hline Professional, technical and managerial & $16(35.6)$ & $59(44.4)$ & $75(42.2)$ \\
\hline Clerical & $10(22.2)$ & $13(9.8)$ & $23(12.9)$ \\
\hline Sales & $6(13.3)$ & $10(7.5)$ & $16(9.0)$ \\
\hline Agriculture employee & $4(8.9)$ & $16(12.0)$ & $20(11.2)$ \\
\hline Service, skilled and unskilled worker & $9(20.0)$ & $35(26.3)$ & $44(24.7)$ \\
\hline \multicolumn{4}{|l|}{ Number of working hours } \\
\hline Less than $8 \mathrm{~h}$ & $11(24.4)$ & $39(29.3)$ & $50(28.1)$ \\
\hline $8 \mathrm{~h}$ and above & $34(75.6)$ & $94(70.7)$ & $128(71.9)$ \\
\hline \multicolumn{4}{|l|}{ Family type } \\
\hline Nuclear & $21(46.7)$ & 65 (48.9) & $86(48.6)$ \\
\hline Joint & $16(35.5)$ & $50(37.6)$ & $66(37.1)$ \\
\hline Extended & $8(17.8)$ & $18(13.5)$ & $26(14.6)$ \\
\hline
\end{tabular}


method (including traditional methods) and any modern method was similar (98.4\%). There was awareness to the extent of $92.7 \%$ about female sterilization. Among the spacing methods of contraception, oral pills (93.8\%), copper T (88.2\%), condom/nirodh (71.9\%) were popular methods of contraception known by participants. Awareness about emergency contraceptives was found to be $18.5 \%$. In natural methods, rhythm method and lactational amenorrhea were mentioned by $26.4 \%$ and $11.2 \%$ respectively. Since 177 women were aware of contraceptives, further participation regarding meaning and use of contraception was limited them only (Table 2 ).

When asked about the meaning of "contraception/family planning" multiple responses were obtained. Majority of them (60.1\%) reported "family planning"|“contraception" as birth spacing, 97 (54.5\%) reported as limiting and 60 (33.7\%) reported as avoiding unintended pregnancy. Unintended pregnancy was defined as pregnancy that was not wanted by the couple at the time of conception whereas unwanted pregnancy was defined as reporting pregnancy when couple don't want any more children. Out of 177, 113 (64.0\%) opinioned that ideal gap between pregnancies should be three years or more. Majority 110 (62.1\%) of participants didn't have sex preference for children. Majority (79.2\%) had desire for two children, 34 (19.1\%) had desire for single child and 3 (1.7\%) had desire for three children.

Out of 177,169 (95.5\%) reported that information on contraception was provided by health personnel. Few received information from mass media like internet (29.9\%) and television (24.9\%). Only $29(16.4 \%)$ respondents told information was provided by family members, following friends (6.2\%) and neighbors (2.3\%). Majority $(52.2 \%)$ received information from the public sector.

Out of 177 working women, contraceptives were currently practiced by only 76 (43\%) of them whereas 101 (57\%) of them were not practicing any method of contraception. Among the users of contraceptives, commonest method was copper $\mathrm{T}$ (44.9\%), followed by rhythm method (23.7\%), male condom (13.2\%), oral pills (9.2\%), injectables (7.9\%) and withdrawal method (3.9\%). Current users were using contraception since an average of $7.47 \pm 4.031$ months. Copper T was practiced by majority (48.8\%) of professionals, technical and managerial women, $50.0 \%$ of clerical women were practicing rhythm method (Table 3 ).

Among the non-users of contraception, majority of participants $70(69.2 \%)$ gave reason that they had fear about side-effects of contraceptives. Out of $102,9(8.9 \%)$ of them were planning pregnancy, 4 (4.0\%) responded saying opposition from their husbands and $12(11.9 \%)$ were practicing abstinence and $2(2.0 \%)$ of them told it decreases sexual pleasure. Only 4 (4.0\%) responded as contraception is against their religious belief (Table 3 ).

The majority of participants (91.6\%) reported they take joint decision about family planning services. Here joint decision was

Table 2

Awareness of specific contraceptive methods (multiple responses) ( $n=178$ ).

\begin{tabular}{lll}
\hline Method of contraception & Frequency & Percentage \\
\hline For any method & 177 & 98.4 \\
For any modern method & 177 & 98.4 \\
Female sterilization & 165 & 92.7 \\
Male sterilization & 62 & 34.8 \\
Copper T & 157 & 88.2 \\
Oral pills & 167 & 93.8 \\
Emergency pills & 33 & 18.5 \\
Injectables & 52 & 29.2 \\
Condom/Nirodh & 128 & 71.9 \\
Implants & 1 & 0.6 \\
Rhythm method & 47 & 26.4 \\
Withdrawal method & 10 & 5.6 \\
Lactational amenorrhea & 20 & 11.2 \\
\hline
\end{tabular}

meant by decision taken by husband and wife together. Only 3 $(1.7 \%)$ of them reported family planning is their own decision and 12 (6.7\%) of them reported family planning is mainly their husbands' choice. Around $60 \%$ had a concern using spacing methods of contraception would affect their future fertility. Out of $177,2.3 \%$ reported religious belief, $14.7 \%$ as the age of the child, $5.1 \%$ reported respondents' working status and $17.5 \%$ as health services which were offered by community health workers during the home visits and health professional in the hospitals such as providing contraceptives, health education on family planning especially on spacing pregnancies made them decide on contraception.

In the present study, there was a significant association between residence $(P=0.020)$, religion $(P=0.027)$, educational status $(P=0.029)$, occupation $(P=0.021)$ and family type $(P=0.001)$ with the current use of contraception (Table 4 ).

\section{Discussion}

In the present study, the mean age of respondents was $29 \pm 3.516$ years. A study done on working women by Takkar et al. in Chandigarh showed almost similar age distribution of 28.2 years. ${ }^{9}$ Most of the respondents were Hindu (85.4\%) by religion. A similar distribution was seen in the study done by Renjhen et al. in Sikkim where majority were Hindus. ${ }^{10}$

Udupi district fact sheet showed awareness for any method and any modern method of contraception was $99.9 \%$ and $99.7 \%$ respectively. ${ }^{11}$ In the present study contraceptive awareness for any method (including traditional as well as modern method) and any modern method was similar (98.4\%).

All the participants except one were aware of at least one modern contraceptive method, which was almost similar to the study conducted by Mekonnen et al. in Butajira district SouthCentral Ethiopia where $99 \%$ of women knew at least one method of contraception. ${ }^{12}$ There was awareness to the extent of $92.7 \%$ about female sterilization but male sterilization was known by only $34.8 \%$, which is very less compared to DLHS data where awareness of male sterilization was $73.8 \% .{ }^{11}$ Since majority of women were given emphasis on spacing methods used by women at the time of discharge from the hospital after the delivery awareness about male sterilization was low. Among the spacing methods of contraception, oral pills (93.8\%), copper T (88.2\%), condom/nirodh (71.9\%) were popular methods of contraception. Almost similar findings were reported by Renjhen et al. in Sikkim. ${ }^{10}$ Awareness about emergency contraceptives was found to be $18.5 \%$ which was higher compared to study done on educated working women by Takkar et al. in Chandigarh. ${ }^{9}$

Majority (79.2\%) had desire for two children; similar finding was seen in study done by Kumar Gupta et al. in Jammu, India. ${ }^{13}$ Out of 177, 34 (19.1\%) had desire for single child. Couples' desire for single child is encouraging in dropping the young age dependency ratio which has implications in promoting mother and child health. Since India's population is aging, over years it adds to raising old age dependency which would affect productivity of the country.

Only 29 (16.4\%) respondents told information was provided by family members, which is very less compared to study done by Gupta et al. in Garhwal, Uttarakhand where they reported 86.24\% of respondents were provided information by family members. ${ }^{14}$

CPR for any method in the present study was reported $43 \%$. This was more than Udupi national family health survey-4 where CPR was reported $32.4 \%$. But CPR in the present study was less in comparison with the national average of $53.5 \%{ }^{15}$ But a study conducted by Rahman et al. in Bangladesh showed CPR 31\% which is lesser than present study. ${ }^{16}$ Among the users of contraceptives, commonest method was copper $\mathrm{T}$ (44.9\%). In a study conducted by Shrividhya et al. in Bangalore, commonest spacing method of 
Table 3

Current use of specific contraceptives method and factors influenced for decision making across working groups.

\begin{tabular}{|c|c|c|c|c|c|c|}
\hline & $\begin{array}{l}\text { Professional, technical and } \\
\text { managerial } \\
n \text { (column \%) }\end{array}$ & $\begin{array}{l}\text { Clerical } \\
n \text { (column } \\
\%)\end{array}$ & $\begin{array}{l}\text { Sales } \\
n \text { (column } \\
\%)\end{array}$ & $\begin{array}{l}\text { Agricultural } \\
\text { employee } \\
n \text { (column\%) } \\
\end{array}$ & $\begin{array}{l}\text { Services, skilled and unskilled } \\
\text { worker } \\
n \text { (column\%) }\end{array}$ & $\begin{array}{l}\text { Total } \\
n(\text { column\%) }\end{array}$ \\
\hline \multicolumn{7}{|c|}{ Current use of contraception $(n=177)$} \\
\hline Yes & $41(54.7)$ & $10(43.5)$ & $3(18.8)$ & $10(52.6)$ & $12(27.3)$ & $76(42.9)$ \\
\hline No & $34(45.3)$ & $13(56.5)$ & $13(81.2)$ & $9(47.4)$ & $32(72.7)$ & $101(57.1)$ \\
\hline \multicolumn{7}{|c|}{ Current use of specific contraceptive method ( $n=76)$} \\
\hline Oral contraceptives & $6(14.6)$ & $0(0.0)$ & $0(0.0)$ & $1(10.0)$ & $0(0.0)$ & $7(9.2)$ \\
\hline Copper $\mathrm{T}$ & $20(48.8)$ & $2(20.0)$ & $1(33.3)$ & $3(30.0)$ & $6(50.0)$ & $32(42.1)$ \\
\hline Male condom & $6(14.6)$ & $2(20.0)$ & $0(0.0)$ & $1(10.0)$ & $1(8.3)$ & $10(13.2)$ \\
\hline Injectables & $1(2.4)$ & $1(10.0)$ & $1(33.3)$ & $3(30.0)$ & $0(0.0)$ & $6(7.9)$ \\
\hline Rhythm method & $5(12.2)$ & $5(50.0)$ & $1(33.3)$ & $2(20.0)$ & $5(41.7)$ & $18(23.7)$ \\
\hline Withdrawal method & $3(7.3)$ & $0(0.0)$ & $0(0.0)$ & $0(0.0)$ & $0(0.0)$ & $3(3.9)$ \\
\hline \multicolumn{7}{|c|}{ Reasons for not using contraception $(n=101)$} \\
\hline Planning pregnancy & $1(2.9)$ & $2(15.4)$ & $2(15.4)$ & $0(0.0)$ & $4(12.5)$ & $9(8.9)$ \\
\hline Husband opposed & $1(2.9)$ & $0(0.0)$ & $1(7.7)$ & $0(0.0)$ & $2(6.2)$ & $4(4.0)$ \\
\hline Religious prohibition & $2(5.9)$ & $0(0.0)$ & $1(7.7)$ & $0(0.0)$ & $1(3.1)$ & $4(4.0)$ \\
\hline Fear of side-effects & $21(61.8)$ & $10(76.9)$ & $6(46.2)$ & $9(100.0)$ & $24(75.0)$ & $70(69.3)$ \\
\hline Abstinence & $8(23.5)$ & $1(7.7)$ & $2(15.4)$ & $0(0.0)$ & $1(3.1)$ & 12 (11.9) \\
\hline $\begin{array}{l}\text { Decreased sexual } \\
\text { pleasure }\end{array}$ & $1(2.9)$ & $0(0.0)$ & $1(7.7)$ & $0(0.0)$ & $0(0.0)$ & $2(2.0)$ \\
\hline
\end{tabular}

Table 4

Association between socio-demographic characteristics and current use of contraception $(n=177)$.

\begin{tabular}{|c|c|c|c|}
\hline Variables & $\begin{array}{l}\text { Current use of contraception (Yes) } \\
n(\%)\end{array}$ & $\begin{array}{l}\text { Current use of contraception (No) } \\
n(\%)\end{array}$ & $P$ value \\
\hline \multicolumn{4}{|l|}{ Residence } \\
\hline Rural & $50(37.9 \%)$ & $82(62.1 \%)$ & \multirow[t]{2}{*}{0.020} \\
\hline Urban & $26(57.8 \%)$ & $19(42.2 \%)$ & \\
\hline \multicolumn{4}{|l|}{ Religion } \\
\hline Hindu & $70(46.4 \%)$ & $81(53.6 \%)$ & \multirow[t]{2}{*}{0.027} \\
\hline Christian and Muslim & $6(23.1 \%)$ & $20(76.9 \%)$ & \\
\hline \multicolumn{4}{|l|}{ Educational status } \\
\hline Secondary education or less & $15(30.0 \%)$ & $35(70.0 \%)$ & \multirow[t]{2}{*}{0.029} \\
\hline Higher secondary and above & $61(48.0 \%)$ & $66(52.0 \%)$ & \\
\hline \multicolumn{4}{|l|}{ Occupation } \\
\hline Professional, technical and managerial & $41(54.7 \%)$ & $34(45.3 \%)$ & \multirow[t]{5}{*}{0.021} \\
\hline Clerical & $10(43.5 \%)$ & $13(56.5 \%)$ & \\
\hline Sales & $3(18.8 \%)$ & $13(81.25)$ & \\
\hline Agricultural employee & $10(52.6 \%)$ & $9(47.4 \%)$ & \\
\hline Services, skilled and unskilled worker & $12(27.3 \%)$ & $32(72.7 \%)$ & \\
\hline \multicolumn{4}{|l|}{ Number of working hours } \\
\hline Less than $8 \mathrm{~h}$ & $22(44.9 \%)$ & $27(55.1 \%)$ & \multirow[t]{2}{*}{0.744} \\
\hline $8 \mathrm{~h}$ and more & $54(42.2 \%)$ & $74(57.8 \%)$ & \\
\hline \multicolumn{4}{|l|}{ Family type } \\
\hline Nuclear & $48(56.5 \%)$ & $37(43.5 \%)$ & \multirow[t]{3}{*}{0.001} \\
\hline Joint & $23(34.8 \%)$ & $43(65.2 \%)$ & \\
\hline Extended & $5(19.2 \%)$ & $21(80.8 \%)$ & \\
\hline \multicolumn{4}{|l|}{ Sex of the living child } \\
\hline Male & $33(37.5 \%)$ & $55(62.5 \%)$ & \multirow[t]{2}{*}{0.146} \\
\hline Female & $43(48.3 \%)$ & $47(51.7 \%)$ & \\
\hline
\end{tabular}

Significance $P<0.005$.

contraception was copper $\mathrm{T} .{ }^{17}$ In the present study, oral contraceptive users were only $9.2 \%$. This is very less compared to a study done by Renjhen et al. in Sikkim which reported $37.9 \%$ were oral contraceptive users. ${ }^{10}$

Majority (69.2\%) of non-users of contraception had fear of sideeffects about modern contraceptives. In developing countries, concerns about side-effects or health risks associated with the modern contraceptives, opposition from the partner, lactational amenorrhea, infrequent sex or not having sex (abstinence) were common reasons cited by women for not using contraception. An increased prevalence of side effect as a reason for not using contraception indicates modern contraceptive technologies have not been adequately addressed these concerns. In present era; women who were not using contraception rarely said that availability, accessibility or affordability as major issues. ${ }^{2,18}$
Only 4 (4.0\%) responded as contraception is against their religious belief which is very less compared to a study done by Mekonnen et al. in South-Central Ethiopia which reported 22.2\%. ${ }^{12}$ In the previous study done in South Ethiopia by Belay et al. revealed that women's employment status contributed to decision making power in family planning use. This finding was parallel with the present study. ${ }^{7}$

Religion was found to have a significant association with the use of contraception $(P<0.027)$, that is, practice of contraception among Hindu was double as compared to Christian and Muslim. Religious prohibition was the reason among Muslim women for not using contraception. This result was consistent with the study done by Gupta et al., Koringa et al. in and Ananth et al. ${ }^{14,19,20}$ In the present study, women's education was found as key determinant with the use of contraception at $P$ value 0.029 , women with higher 
secondary education and above were more likely to practice contraception than women who had secondary education or below. A similar association was found in the study done by Belay et al., Halder et al., Mekonnen et al., Gupta et al., Koringa. $7,8,12,14,19$ But these results were in contrary to the finding of study done in Kerala by Anant et al. ${ }^{20}$ Couples in the nuclear family had more freedom to take decision, they had a higher acceptance rate and it was significant at the $P$-value 0.001 . A similar result was reported in a study done by Pushpa et al. in Dharwad district and Halder et al. in West Bengal, India. ${ }^{4,8}$ Contraceptive use was also significant with occupation at $P$ value 0.021 , professional, technical and managerial women practiced contraception more as in comparison with clerical women, women involved in sales, agricultural women and women working in services, skilled and unskilled works. Number of working hours and sex of the living child didn't have any influence on the contraceptive use. Present study reflects that increased educational level made women to decide on contraceptive use. Staying in nuclear families increased freedom to decide on contraception. Economic independence had also added a significant impact on the use of contraception.

\section{Conclusion}

The study examined contraceptive knowledge and practice among working women from rural and urban areas of Udupi taluk. Although the majority had knowledge of contraceptives, less than half of the women were practicing contraception. Copper T was the commonest method preferred by working women. Majority of working women were not using contraception because of fear of side-effects. Decision making regarding family planning services was based upon mutual discussion between husband and wife. Social factors like residence, religion, educational status, occupation, family type were found to influence contraceptive practice.

\section{Limitation}

Field level tool validation was not done.

\section{Recommendations}

Choosing the most appropriate method of contraception and removing unnecessary barriers can help working women successfully use contraceptive methods for a longer period of time. Routine follows up of working women at the workplace which includes health check-up along with the assessment of her satisfaction and concerns with the method used should be done. There is a need to motivate working women for the contraceptive use.

\section{Acknowledgement}

We express our deep sense of gratitude whole heartedly to all the participants of the study for their time and cooperation during the data collection and to the Department of Public Health, Manipal University, Manipal.

\section{References}

1. World Health Organization. Family Planning/Contraception Fact Sheet. Available from: http://www.who.int/mediacentre/factsheets/fs351/en/.

2. United Nation. Department of Economic and Social Affairs. Trends in Contraceptive Use Worldwide. 10.1016/j.contraception.2012.08.029.

4. Pushpa SP, Venkatesh R, Shivaswamy MS. Study of fertility pattern and contraceptive practices in a rural area - a cross-sectional study. Indian J Sci Technol. 2011;4(April (4)):429-431.

5. NFHS-3. International Institute for Population Sciences (IIPS) and Macro International. National Family Health Survey (NFHS-3); 2005-06.

6. Pachauri S. Expanding contraceptive choice in India: issues and evidence.J Fam Welf. 2004;50:13-25.

7. Belay AD, Mengesha ZB, Woldegebriel MK, Gelaw YA. Married women's decision making power on family planning use and associated factors in Mizan-Aman, South Ethiopia: a cross sectional study. BMC Women's Health. 2016;16(12):1-6

8. Haldar A, Baur B, Das P, Misra R, Pal R, Roy PR. Contraceptive practices and associated social covariates: an experience from two districts of West Bengal, India. NepJOL. 2012;2(4):219-225.

9. Takkar N, Goel P, Saha PK, Dua D. Contraceptive practices and awareness of emergency contraception in educated working women. Indian J Med Sci. 2005;59(4):143-149.

10. Renjhen P, Gupta SD, Barua A, Jaju S, Khati B. Family planning practices in women of reproductive age group in Sikkim. J Obstet Gynecol India. 2008;58 (1):63-67.

11. District level household and family survey (DLHS-4) - Factsheet Karnataka (2012-2013). International institute for population sciences.

12. Mekonnen W, Worku A. Determinants of low family planning use and high unmet need in Butajira district, South Central Ethiopia. Reprod Health. 2011;8 (1):1-8.

13. Gupta RK, Verma AK, Shora TN. Contraceptive prevalence, attitude and choice among women of reproductive age group in a rural area of Jammu, India. PHR. 2013;3(4):92-97.

14. Gupta SK, Dixit S, Singh AK, Nagaonkar SN. Contraceptive practices among eligible couples: a cross sectional household survey in eligible couples of urban population of Garhwal - Uttarakhand. JARMS. 2013;6(1):39-42.

15. NFHS-4. International Institute for Population Sciences (IIPS) and Macro International. National Family Health Survey (NFHS-4); 2015-16.

16. Rahman A, Rahman M, Siddiqui MR, Zaman JA. Contraceptive practice of married women: experience from a rural community of Bangladesh. JM. 2014;15(1):9-13.

17. Srividya V, Kumar J. Family planning practices prior to the acceptance of tubectomy: a study among women attending a maternity home in Bangalore, India. JCDR. 2013;7(8):1640-1643.

18. Reasons for Unmet Need for Contraception in Developing Countries. Guttmacher institute; 2016 Available from: https://www.guttmacher.org/report/unmetneed-for-contraception-in-developing-countries.

19. Koringa HT, Joshi KJ, Mehta JP. A study on various factors affecting family planning practices among eligible couples in urban slums of municipal corporation area in Jamnagar, Gujarat, India. IJMSPH. 2015;4(12):1675-1680.

20. Ananth PT, John A, Kumar D. Family planning practices in rural Kerala. SJAMS. 2014;2(1A):19-21.

\section{Conflicts of interest}

The authors have none to declare. 